\title{
Education and the Global Fertility Transition- Foreword
}

\author{
K.S. James, Vegard Skirbekk and Jan Van Bavel*
}

The 2012 issue of the Vienna Yearbook of Population Research presents a series of studies with one shared focus: Examining the global fertility transition in the light of educational change.

Special attention is given to changes in basic and more advanced school attainment and the implications for the timing and outcome of fertility. Several key channels through which education growth affects fertility are investigated, ranging from its effects on female financial autonomy to the effects on marriage markets characterised by high levels of educational homogamy. The studies address the whole range of fertility transitions from the early high fertility stages to low fertility in developed countries.

The rise of education levels is widely seen to be among the key causes of fertility decline during the demographic transition (Basu 2002; Martin and Juarez 1995; Cleland 2002). Education tends to delay the onset of fertility and depress fertility outcomes. These effects are likely to be causal and not solely driven by selection into schooling (e.g. that those who would have fewer children anyway attain higher education). Studies based on exogenous variation in the school leaving age (which is not associated with any other individual characteristics) support this. For instance, expansions to compulsory school length in Turkey lead to significantly lower fertility among teenagers (Kırdar, Dayığlu and Koç 2011). Likewise, in Sweden, school laws that cause variation in the school leaving exit age based on birth month has been found to have the effect, for those who exit school at a higher age, that they marry later and have their first and second childbirth at older ages (Skirbekk, Kohler and Prskawetz 2004).

Individuals have always strived for status, and one reason for this is that status could increase the mating opportunities and the number of offspring (Skirbekk 2008; Rueden, Gurven and Kaplan 2010). Traditionally, individuals of higher

\footnotetext{
* Vegard Skirbekk (correspondence author), International Institute for Applied Systems Analysis (IIASA), Laxenburg, Austria. Email: skirbekk@iiasa.ac.at

K.S. James, Population Research Centre, Institute for Social and Economic Change, Nagarabhavi P.O. Bangalore-560072, India.

Jan Van Bavel, Centre for Sociological Research / Family and Population Studies, Faculty of Social Sciences, University of Leuven, 3000 Leuven, Belgium.
} 
socio-economic status tended to have more children, see Figure 1. Conventional status measures - income, wealth, hierarchy position or occupational statuswere historically found to raise fertility levels. Over time, however, the fertility differentials became less pronounced, particularly in the latter half of the 20th century. Education, on the other hand, has been found to be negatively associated with fertility for as long as it has been measured. Education is likely to have increased in importance as a status-defining characteristic over the 20th century. Figure 1 presents findings from a meta-analysis on how relative fertility by status changed over time globally. Here income/wealth or occupational/ social class in recent years tend to not strongly relate to fertility levels, while education clearly has a negative effect on fertility.

\section{Figure 1:}

An analysis of status and fertility from year 1300 to 2005 globally. Fertility of high status individuals relative to those with low social status (in per $\mathrm{ce}^{-4}$ )

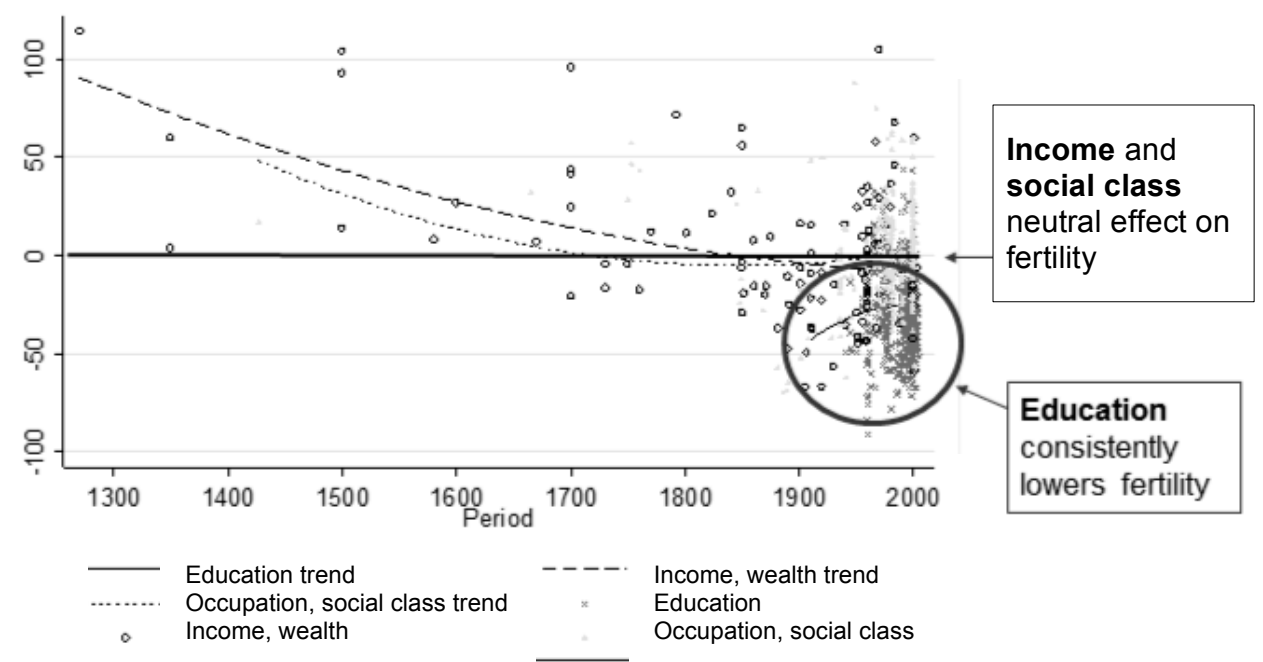

Source: Skirbekk 2008 .

Education may operate as a self-reinforcing status-seeking spiral mechanism, with important consequences for aggregate fertility over time. Later-born cohorts of women, in order to maintain a given position in the education distribution compared to their same-age peers, must attain increasingly higher levels of education. This implies that the process of status-seeking is having increasingly strong effects in terms of reducing global fertility levels (Skirbekk and KC 2012), see Figure 2. 
Figure 2:

Stylised diagram showing status attainment via education in the historic regime, where status tended to be determined early in life, and the contemporary regime, where status is determined in adult life - and their impact on the timing of fertility

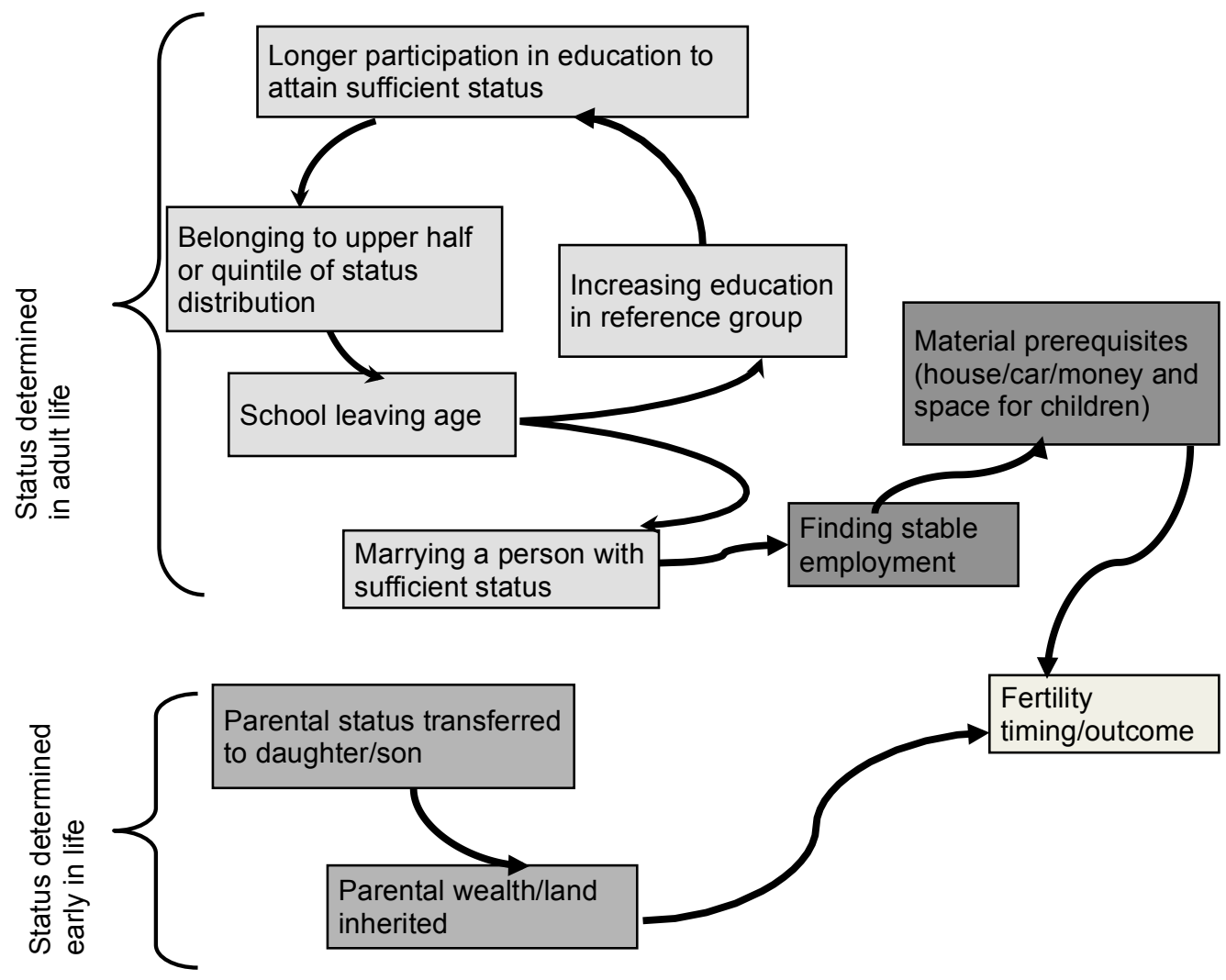

Source: Skirbekk and KC 2012

Today, especially secondary education seems to be an important driver of fertility limitation in many developing countries (Cohen 2008). This can be particularly important for Asian nations where schooling levels have risen rapidly in recent decades and there has been both an increase in the ages at childbearing and a reduction in the total fertility rate (Figure 3 ). 
Figure 3:

TFR and median school leaving age: Asian* countries observed in five-year intervals, 1970-2000

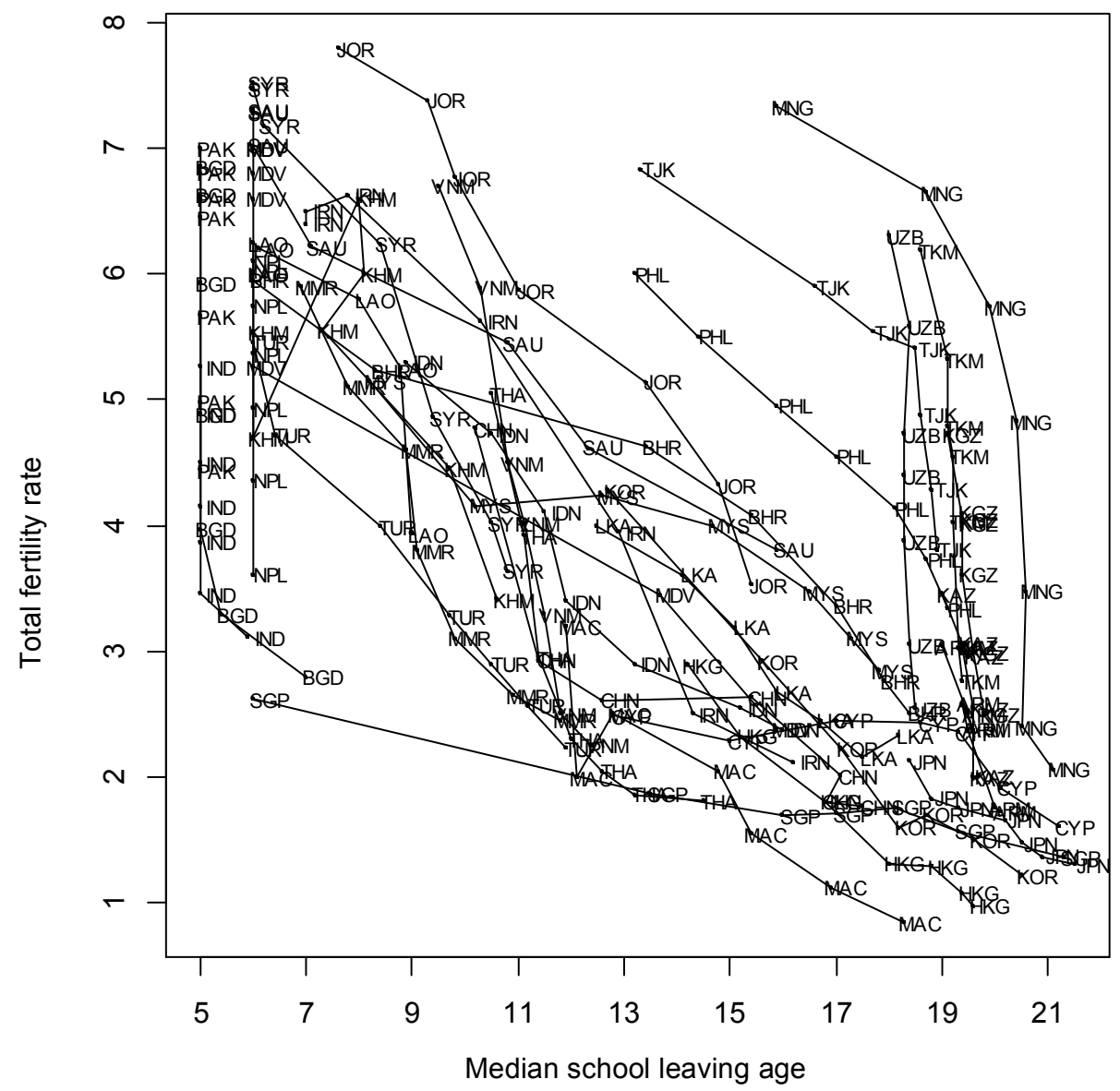

Notes: ${ }^{*} \mathrm{CHN}=\mathrm{China}$; $\mathrm{HKG}=\mathrm{China}$, Hong Kong SAR; MAC $=$ China, Macao SAR; JPN=Japan; $\mathrm{MNG}=$ Mongolia; KOR=Republic of Korea; $\mathrm{BGD=Bangladesh;} \mathrm{IND=India;} \mathrm{IRN=Iran} \mathrm{(Islamic} \mathrm{Republic} \mathrm{of);}$ $\mathrm{KAZ}=$ Kazakhstan; $\mathrm{KGZ}=$ Kyrgyzstan; $\mathrm{MDV}=$ Maldives; $\mathrm{NPL}=$ Nepal; $\mathrm{PAK}=$ Pakistan; LKA=Sri Lanka; TJK=Tajikistan; TKM=Turkmenistan; UZB=Uzbekistan; KHM=Cambodia; IDN=Indonesia; LAO=Lao People's Democratic Republic; MYS=Malaysia; MMR=Myanmar; $\quad \mathrm{PHL}=$ Philippines; SGP=Singapore; THA=Thailand; VNM=Viet Nam; ARM=Armenia; BHR=Bahrain; CYP=Cyprus; JOR=Jordan; SAU=Saudi Arabia; SYR=Syrian Arab Republic; TUR=Turkey.

Source: IIASA education database (KC et al. 2010).

Several channels can explain the causal pathways between education and fertility dynamics. Education often implies that childbearing behaviour is increasingly a rational behaviour - where decisions on the timing and quantum of fertility are weighted against perceived implications for other life goals, such as careers, consumption and self-realisation. Schooling can affect the optimal timing 
for initiating childbearing and also the perceived ideal number of children. Education relates to better contraceptive use, changes in sexual behaviour, changes in preferences for "child quality" and investments in children. Schooling can, on the other hand, increase one's ability to actually fulfil personal fertility preferences. However, it may also change the concept of 'social success' in life, where having (many) children may become less important compared to other achievements. People with more education may place a higher emphasis on, for instance, academic success, occupational prestige, self-realisation and other factors that could potentially be in conflict with parenting. Education is a key driver of skills and cognitive competences, and its effects, such as literacy and cognitive skills can raise female empowerment and economic opportunities for women.

The present issue of the VYPR contains original articles that shed light on several of these questions and could increase our understanding of the importance of considering the relationship between education and fertility.

In the first article of this issue, David Shapiro considers childbearing in subSaharan Africa. This region has some of the highest fertility in the world-and also some of the lowest education levels. The impact of education is explored in the context of declining infant and child mortality and changes in economic wellbeing and the author stresses the significant role of increasing enrolment in secondary and higher schools for the process of fertility transition.

Onipede Wusu studies Nigerian fertility between 1990 and 2008. The author considers the relative impact of female education and labour force participation in terms of their effects on fertility. Although the proportion of illiterate women in the country declined from $57.2 \%$ to $35.8 \%$ in this period, fertility remains high. The total fertility rate in Nigeria has been fluctuating between 6.6 and 5.6 since 1965. Given the country's TFR, Wusu argues that there is no signal a sustainable fertility decline will be realised at some point. Wusu finds female education to be inversely related to the indicators of fertility, but the relationship with employment is less clear. He concludes that female education remains a valid channel through which sustainable fertility decline can be achieved in Nigeria.

Nauck and Tabuchi study family change in Japan, a collectivistic country, and Germany, a society characterised more by individualism. They compare the "second demographic transition" model (Lesthaeghe 2010) with that of "family change"(Kağıtçıbaşı). They study how schooling has affected fertility over the last 60 years. Although the changes point in the direction predicted by the second demographic transition model, they find that the differences between the two societies have remained stable or even widened, in line with the family change model.

Esteve, Spijker, Riffe and García look at school enrolment and union status/parenthood among females aged 15-24 (adolescents and young adults) in 55 low- and middle-income countries. They find that higher shares studying are strongly negatively correlated with the population shares in spousal and parental 
roles-because students are less likely to marry or have children compared to non-students.

Bordone and Weber focus on the relationship between cognition and fertility in an in-depth study of the SHARE data for Europe. The analyses focus on the older population, their cognitive ability level and their number of children. They find a positive association between cognitive functioning and having children versus being childless. Interestingly, parents of two children show higher abilities than both parents of a single child and heads of large families.

Jan van Bavel provides a set of interrelated hypotheses about the implications of changes in relative education between the genders for fertility. While men were better educated historically, there are now more highly educated women than men reaching the reproductive ages and looking for a partner in Europe as well as in many other countries. He discusses effects on union formation patterns, where the traditional pattern of female hypergamy (i.e. women mating men who are at least as highly educated as themselves) is no longer compatible with the new gender distribution in education. He expects a new, education-specific mating squeeze to emerge that will affect the process and outcome of assortative mating, which in turns is going to affect the timing, probability and stability of union formation. Van Bavel formulates hypotheses about the implications for future fertility trends and patterns in Europe and similar Western regions.

\section{Education and fertility in different context}

From the above discussion, can we unequivocally conclude on the universal existence of an education-fertility link irrespective of contexts? Although the articles in this volume are not exhaustive and do not cover evidence from all regions, the available data provide a nearly uniform affirmative conclusion on this relationship. However, it would be interesting to ask whether there any instances of this education-fertility link being either weak or not even existing in any other parts of the world. Providing conclusive evidence on this invariably requires analysis of both macro- and micro-level data in detail. While the individual-level data across contexts present strong evidence of a close connection between education and fertility, such vast data material often does not come from macrolevel analysis. The macro-level evidence available from some of the Asian countries which have strong family-planning programmes is rather mixed. For instance, James (James 2011) argues that in many states of India, the fertility decline did not go hand in hand with educational progress. In the case of China, it is argued that while education does have a link with fertility, it may not be the cause of fertility transition (Lavely and Freedman 1990). In a way, these studies only indicate the possibility of other predictors which may also apply in a some specific context, weakening the role of education but not completely negating its importance. Jejeebhoy argued that levels of schooling are highly context-specific and as such may not all have a universal link with fertility to the same degree of intensity (Jejeebhoy 1995). 
The connection between education and fertility should also be viewed in connection with child mortality and, therefore, within the larger framework of the demographic transition. Sustained fertility decline has never been achieved without reductions in child mortality: nowhere in the world will people limit their fertility if they cannot be certain that their limited progeny will survive to adulthood (see also Lee 2003; Soares 2005). There is very strong evidence of improved survival chances of children with increasing education of the parents, and of the mother in particular (Hobcraft 1993). Therefore, the expansion of education may have a two-way multiplier effect on reducing fertility in highfertility countries. First, it acts to increase the survival chances of children. Second, the expansion of education motivates people to limit their fertility and leap from investing in child quantity towards investing in child quality. The former effect reinforces the latter one: increased child survival promotes fertility reduction. And vice versa: decreased fertility also reduces infant and child mortality.

It also raises another important question on the role of education in contexts where the fertility transition is nearly achieved: in other words, is there any evidence to suggest that the education-fertility link weakens in a low-fertility context? Perhaps not. The available studies do not give any support for such an indication. Although the variations in fertility due to different educational levels are reduced in low fertility settings, in absolute terms there is less variance left to be explained by education or anything else. Thus it appears that the educationfertility link is something which is universal in nature, irrespective of culture, context, geography or the level of fertility transition.

\section{Acknowledgment}

We acknowledge support by a Starting Grant of the European Research Council, Grant Agreement 241003-COHORT.

\section{References}

Basu, A.M. 2002. "Why Does Education Lead to Lower Fertlity? A Critical Review of Some of the Possibilities." World Development 30: 1779-1790.

Cleland, J. 2002. Education and Future Fertility Trends, with Special Reference to Midtransitional Countries. Background Papers. Completing the Fertility Transition. Part 2. New York: United Nations, Population Division, Department of Economic and Social Affairs.

Cohen, J.E. 2008. “Make Secondary Education Universal.” Nature 456(7222): 572-573.

Hobcraft, J. 1993. "Women's Education, Child Welfare and Child Survival: a Review of the Evidence." Health Transition Review 3(2): 159-175. 
James, K.S. 2011. “India's Demographic Change: Opportunities and Challenges.” Science 333(6042): 576-580.

Jejeebhoy, S. 1995. Women's Education, Autonomy and Reproductive Behaviour: Experience from Developing Countries. Oxford: Clarendon Press.

Kağıtçıbaşı, C. 2006. "Theoretical perspectives on family change." In Families Across Cultures. A 30-Nation Psychological Study, ed. J. Georgas, J.W. Berry, F.J.R. van de Vijver, C. Kağıtçıbaşı and Y.H. Poortinga, 72-89. Cambridge, UK: Cambridge University Press.

KC, S., B. Barakat, A. Goujon, V. Skirbekk, W.C. Sanderson and W. Lutz. 2010. "Projection of Populations by Level of Educational Attainment, Age, and Sex for 120 Countries for 2005-2050." Demographic Research 22: 383-472.

Kırdar, M., M. Dayığlu Tayfur and I. Koç. 2011. "The Effect of Compulsory Schooling Laws on Teenage Marriage and Births in Turkey." IZA 5887.

Lavely, W. and R. Freedman. 1990. "The Origins of the Chinese Fertility Decline." Demography 27(3): 357-367.

Lee, R.D. 2003. "The Demographic Transition: Three Centuries of Fundamental Change." Journal of Economic Perspectives 17(4): 167-190.

Lesthaeghe, R. 2010. "The Unfolding Story of the Second Demographic Transition." Population and Development Review 36(2): 211-251.

Martin, T.C. and F. Juarez. 1995. "The Impact of Women's Education on Fertility In Latin America: Searching for Explanations." International Family Planning Perspectives 21(2): 52-80.

Rueden, C. von, M. Gurven and H. Kaplan. 2010. "Why Do Men Seek Status? Fitness Payoffs to Dominance and Prestige." Proceedings of the Royal Society B: Biological Sciences 278(1715): 2223-2232.

Skirbekk, V. 2008. "Fertility Trends by Social Status." Demographic Research 18(5): $145-180$.

Skirbekk, V. and S. KC. 2012. "Fertility-reducing Dynamics of Women's Social Status and Educational Attainment." Asian Population Studies (article in press).

Skirbekk, V., H.-P. Kohler and A. Prskawetz. 2004. "Birth Month, School Graduation, and the Timing of Births and Marriages." Demography 41(3): 547-568.

Soares, R.R. 2005. "Mortality Reductions, Educational Attainment, and Fertility Choice." The American Economic Review 95(3): 580-601.

UN. 2011. World Population Prospects. New York: United Nations Population Division. 